\title{
A EXPRESSÃO DA REFORMA DE ANTÓNIO RODRIGUES SAMPAIO NO MUNICÍPIO DE LISBOA OU A AFIRMAÇÃO DE UM "GOVERNO DOS ASSUNTOS EDUCACIONAIS"
}

\author{
Carlos Manique da Silva*
}

\begin{abstract}
RESUMO
Este artigo procura captar a ação educativa do município de Lisboa durante a primeira grande experiência descentralizadora do ensino, enquadrada pela Reforma de António Rodrigues Sampaio (Lei de 2/5/1878). Ao longo da década de 1880, período em que decorre a referida experiência, a Câmara de Lisboa, na assunção de uma vontade local e procurando dar corpo a um projeto republicano de educação popular, protagoniza um interessante movimento de renovação educacional. O Estado, no entanto, tenta a todo o custo refreá-lo. Mas a verdade é que a iniciativa reformadora da Câmara prossegue bem explícita nos seus objetivos e firmada numa série de medidas e realizações. É paradigmática, por exemplo, a aposta na escola graduada (ou central). Trata-se, porém, de uma dinâmica que contrasta com a da generalidade dos outros municípios do país, destituídos de uma elite política forte e de recursos financeiros.
\end{abstract}

Palavras-chave: Descentralização do ensino. Renovação educacional. António Rodrigues Sampaio.

\begin{abstract}
This article seeks to capture the educational action of Lisbon's municipality during the first great experience of education decentralization framed by António Rodrigues Sampaio reform act (05/02/1878). Throughout the 1880 s, a period where that experience took place, the municipality leads an interesting movement of educational reform giving expression to a local will concerning a republican project of popular education. The central government, however, tried to stop it. But the truth is that the initiative proceeds very explicit in its objectives supported by various measures and achievements. It is paradigmatic, for instance, the investment in the graded school. This is,
\end{abstract}

\footnotetext{
* Doutor em Ciências da Educação. Investigador do Instituto de Educação da Universidade de Lisboa.E-mail:manique@net.sapo.pt
} 
afterwards, a contrasting dynamic from the other municipalities, where the political elite and financial resources aren't so strong.

Keywords: Decentralization of education. Educational reform. António Rodrigues Sampaio.

\section{Introdução}

Em março de 1886, em plena década de descentralização do ensino, Bernardino Machado refere o pelouro da instrução do município de Lisboa com o intuito de justificar a criação de um Ministério da Instrução Pública; considera-o, então, equivalente «pela capacidade e dinamismo a um governo dos assuntos educacionais» (citado em FERNANDES, 1985, p. 45). Apenas quatro anos volvidos, num discurso proferido no dia $16 \mathrm{de}$ julho de 1890, avança com esse mesmo exemplo (nem outro melhor poderia ser dado) para condenar a lógica centralizadora que presidiu à recente formação do Ministério da Instrução Pública e Belas-Artes (Decreto de 5/4/1890), e exatamente pelo facto de pôr em causa as «relações do Estado com as localidades no governo do ensino» (MACHADO, 1890, p. 21).

O que se acaba de ler é suficiente para se antecipar que a primeira grande experiência descentralizadora do ensino, enquadrada pela Reforma de António Rodrigues Sampaio (Lei de 2/5/1878), assume características muito diferenciadas entre o que foi a dinâmica educativa do município de Lisboa e a dos demais. É, aliás, a partir dessa ideia que um ator como Teófilo Ferreira, num discurso de igual modo pronunciado na Câmara dos Deputados a 26 de junho de 1890, quando se sente já o regresso às políticas de centralização ${ }^{1}$, renuncia ao seguinte princípio doutrinário:

E eu, que defendi e sustentei a descentralização do ensino primário, vi-me obrigado a abjurar dos meus princípios em presença das contínuas, insistentes e quotidianas reclamações feitas pelos meus

\footnotetext{
1 Antes mesmo da criação do Ministério da Instrução Pública e Belas-Artes (agosto de 1890), o Decreto de 27/2/1890, que altera em alguns pontos o Regulamento da Lei de 2/5/1878 (Decreto de 28/7/1881), anuncia novo período de centralização do ensino.
} 
colegas no magistério [...] é necessário que nos convençamos que a província não é Lisboa. $\mathrm{O}$ que se passa nos concelhos sertanejos com os professores de instrução primária é simplesmente horroroso (FERREIRA, 1890, p. 15).

É, de facto, preciso referir em lugar à parte a política educativa do município de Lisboa durante os anos de 1880 - se bem que tudo comece antes, precisamente no início da década anterior, com as medidas que conduzem à criação do pelouro da instrução, em 1873, sob os auspícios de José Elias Garcia $^{2}$-, no essencial por romper com a lógica administrativa do poder central; isto é, os corpos constituídos, designadamente o pelouro da instrução e a junta escolar, definem a sua orgânica em função de problemas concretos, ensaiando no fundo soluções adaptadas ao terreno pedagógico. Mas tudo isto acontece (e incluo aqui a procura da inovação educacional) excedendo o enquadramento da Lei de $2 / 5 / 1878$, dando consequentemente origem, não raras vezes, a um clima de tensão entre o município e o governo central, que tenta de resto impor mecanismos de controlo. E se fosse preciso reduzir a dicotomia nacional/local a um único exemplo, escolheria certamente o seguinte: um ofício dirigido pelo inspetor José António Simões Raposo ao presidente da Câmara Municipal de Lisboa, corria o ano de 1883; veja o leitor que estamos a falar do mesmo Simões Raposo que, em 1868, nas conferências pedagógicas de Lisboa, propusera a adequação dos programas às necessidades locais (GHIRA, 1868). Agora, as palavras do inspetor da primeira circunscrição alinham pela letra da Lei de 2/5/1878, sublinhando que, em assunto de organização escolar, a competência legal das câmaras municipais se limita à definição universal da hora de entrada e de saída da escola (artigo 17. ${ }^{\circ}$ ). Escutemo-lo:

Estas disposições legais e protetoras do ensino público, que tão categoricamente restringem as atribuições dos corpos administrativos são na verdade previdentes, e devemos julgar que foram sabiamente calculadas e maduramente meditadas pelo governo, não só para marcar a intensidade e a extensão da instrução primária nacional,

2 Elias Garcia era engenheiro militar de formação. Foi também deputado e membro da maçonaria portuguesa a partir de 1853, tendo mesmo sido eleito grão-mestre em 1885. 
mas também para dar-lhe a unidade, a harmonia, a fixidez e o carácter genérico que ela deve ter para que corresponda ao modo de ser da sociedade portuguesa. E esta unidade harmónica é tão necessária ao ensino público [que] não poderia jamais alcançar-se se a cada câmara municipal do país fosse permitido intervir direta e liberrimamente nos assuntos literários da escola, com o seu critério individual caraterístico, local, decerto muito apreciável e muito ilustrado, mas sem a competência profissional e sem o ponto de vista superior que carateriza o magistério e justifica o poder central em todas as conceções de interesse geral (Arquivo Histórico da Câmara Municipal de Lisboa, Correspondência Recebida, B 039/01, ofício de 15/1/1883, documento s. p. ).

Com todas estas considerações - salientando as últimas o papel central que a Lei de 1878 atribui à inspeção do ensino - é agora possível expor de forma clara o objetivo deste texto. Passa ele, fundamentalmente, por captar as linhas de força da ação educativa do município da capital no período compreendido entre 1878 , data da publicação da citada Reforma de Rodrigues Sampaio, e 1891, ano em que os serviços de instrução primária a cargo da Câmara Municipal de Lisboa são transferidos para o Estado (Decreto de 26/9/1891). O que se pretende, no fundo, é registar de que forma se traduz a vontade de autonomia na condução das políticas educativas.

\section{Da publicação à regulamentação da Reforma de António Rodrigues Sampaio (1878-1881)}

Até à passagem da gestão do ensino primário para os municípios no dia 1 de julho de 1881, data em que efetivamente começa a ser executada a Lei de $2 / 5 / 1878^{3}$, a Câmara de Lisboa mantém uma atitude de prudência e reserva (não de inércia, todavia). Compreensível. Estava-se, no sugestivo

\footnotetext{
3 Só em 1 de julho de 1880 é nomeada pelo ministro do Reino a comissão encarregue de elaborar os regulamentos e os programas destinados à execução da lei de $2 / 5 / 1878$, entretanto modificada e acrescentada pela Lei de 11/6/1880. O regulamento para a execução das duas leis foi publicado, como já se disse, em 28/7/1881.
} 
dizer de Teófilo Ferreira, «num verdadeiro período de suspensão, e quaisquer trabalhos empreendidos, e mesmo realizados, poderiam em pouco tempo ser inutilizados por alguma disposição regulamentar» (FERREIRA, 1883, p. 135). Porém, o debate educativo não deixa de se intensificar, e o tópico mais sensível, pleno de implicações no período de descentralização, é sem sombra de dúvida o da nomeação dos professores (assunto ao qual regressarei mais tarde).

Considere-se, entretanto, um facto da maior relevância-a publicação do Código Administrativo de 1878 (Carta de Lei de 6 de maio). Trata-se, impõe-se dizê-lo, de um texto sabiamente mobilizado pelos responsáveis do pelouro da instrução do município de Lisboa durante os anos de 1880, a ponto de constituir, por exemplo, instrumento de legitimação das escolas graduadas ou centrais. Na verdade, e apesar da Lei de $2 / 5 / 1878$, no seu artigo $20 .^{\circ}$, prever a existência de escolas com três ou quatro docentes (embora sujeitas a autorização do governo), bem como a Lei de 18/7/1885 (Reforma administrativa do município de Lisboa), a Câmara, na assunção de uma vontade local, justificará, em regra e quando solicitada, a criação desses estabelecimentos de ensino ao abrigo do referido Código (artigo 103. ${ }^{\circ}$, n. $\left.^{\circ} 4\right)^{4}$, prescindindo pois da permissão do poder central.

Deve, aliás, ser salientado que o sucesso do projeto republicano de educação popular para a cidade de Lisboa, no decénio de 1880, muito ficará a dever a esse tipo de prática, as vereações ultrapassarem por vezes as suas competências - «excesso de zelo» desculpável, na avaliação de um observador atento como Bernardino Machado (1890, p. 49).

Interessa, de facto, reconhecer que a implantação dessa lógica no pelouro da instrução ganha corpo no triénio correspondente ao segundo mandato de Elias Garcia (1878-1881). Elucidemo-la, então, com uma das questões mais sensíveis desse mandato e já aqui mencionada: a nomeação dos docentes. O problema, se bem que distinto, não era dissociável do da própria organização do pelouro, cuja secretaria, importa afirmá-lo, fora extinta pelo governo em 1876, tal como os lugares de provedor e de

\footnotetext{
4 O articulado em causa definia como competência das câmaras a criação de estabelecimentos municipais de beneficência, instrução e educação (Código Administrativo aprovado por carta de lei de 6 de maio de 1878, Lisboa: Imprensa Nacional, 1910).
} 
secretário. Neste caso, estávamos em 1879, tanto o vereador responsável pelo pelouro como outro destacado interveniente no debate educativo, o vereador Teófilo Ferreira, concordavam que tais funcionários deveriam ser pessoas de confiança do vereador da instrução, prescindo-se pois de concurso ${ }^{5}$. Porém, interpretação diferente suscitava a escolha dos professores, com duas soluções a serem equacionadas. Precisemo-las: por um lado, afigurava-se óbvio nomeá-los sem concurso documental, contornando na prática o artigo $30 .^{\circ}$ da Lei de $2 / 5 / 1878$, posição frontalmente assumida pelo responsável do pelouro ${ }^{6}$; por outro, sustentavase a necessidade do concurso - e não apenas documental, mas público como forma de «aquilatar o mérito relativo de cada um dos indivíduos que se apresentassem para exercer o professorado» (FERREIRA, 1883, p. 123). Tal era, de facto, a convicção de Teófilo Ferreira.

O que me interessa desde logo notar é que o caminho seguido por via de regra, no caso das escolas centrais, a nomeação sem concurso - dará os melhores resultados nos anos de 1880, permitindo conciliar a expansão do ensino com aspetos de natureza qualitativa, ou seja, sem nunca perder de vista a criação de escolas modelares. Este objetivo era algo indissociável, sabemo-lo bem, da existência de um corpo homogéneo de professores. Esse nexo começa para o historiador a desenhar-se no final do ano de 1881, portanto, já em período de gestão descentralizada, quando o município desaloja duas dezenas de professores das escolas paroquiais (ou de classe única) com o intuito de os colocar nas centrais, entretanto criadas (FERREIRA, 1883). E, conquanto não tenha havido unanimidade em torno desse procedimento, é a sua institucionalização que, em primeira instância, tornará mais relevante a ação educativa do pelouro ao longo da década de 1880 .

\footnotetext{
5 O pelouro da instrução é reorganizado no ano de 1879, regressando João José de Sousa Teles ao lugar de provedor (que mantém até ao final do período de descentralização, 1891, portanto).

6 Contextualize-se que, para além de autorizar a criação de estabelecimentos de ensino, o Código Administrativo de 1878, no n. ${ }^{\circ} 9$ do seu artigo $103 .^{\circ}$, definia ser competência camarária nomear os professores cujos vencimentos, na totalidade ou em grande parte estivessem a cargo do erário municipal (Código Administrativo aprovado por carta de lei de 6 de maio de 1878...). Nesse texto legal se firmava a posição de Elias Garcia.
} 
Esta ideia emerge com particular evidência num ofício que Teófilo Ferreira na qualidade de vereador da instrução dirigiu ao presidente da Câmara Municipal de Lisboa, em 14/12/1882 (portanto, já em período de gestão descentralizada). O longo texto emite, no fundo, uma opinião desfavorável em relação ao procedimento do inspector da $1 .{ }^{a}$ circunscrição escolar Simões Raposo, e muito justamente por este ter contestado a nomeação sem concurso documental da professora Matilde Bachelay Mira (transferida da escola paroquial da freguesia de Santa Catarina para a Central n. $\left.{ }^{\circ} 12\right)^{7}$. Teófilo Ferreira começa por frisar que mais não fizera do que «seguir praxes [...] assentes no pelouro», para logo orientar o seu discurso num registo muito crítico e menos comedido:

Provavelmente o Sr. Inspetor desejava e quereria que continuassem por aí esses antros asquerosos e imundos denominados escolas paroquiais. Fizemos-lhe a vontade, se não no todo, pelo menos em parte, conservando ainda algumas que temos cuidadosamente guardado como padrões eternos de vergonha e aviltamento (Arquivo Histórico da Câmara Municipal de Lisboa, Ofícios Expedidos, B025/01, ofício de 14/12/1882, documento s. p. ).

E se é certo que as citadas palavras traduzem um aspeto contraditório do pensamento de Teófilo Ferreira - falo, claro, da nomeação dos docentes ${ }^{8}$ -, não menos verdadeiro será ver nelas a expressão de uma vontade de autonomia na condução das políticas educativas. Uma vontade que tem como fulcro o novo modelo de organização escolar: a escola graduada ou central.

7 De acordo com o artigo $73 .^{\circ}$ (da Lei de 2/5/1878), e é esse o sentido da argumentação do inspetor, nenhuma escola em exercício poderia ser suprimida, algo que acabava na prática por suceder com o desalojamento dos professores das escolas paroquiais.

8 A este propósito, escutemos o que Teófilo Ferreira afirmara em sessão da Câmara de 24/10/1881: «Em minha opinião [...] a câmara não pode autorizar a nomeação de novos professores sem concurso, e se o fizer pode compelir os magistrados que interferem na execução das novas leis de instrução primária a fazer-lhe interpretar convenientemente o que é de si claro e óbvio; porque os maus exemplos sendo contagiosos, podem comunicarse a outras municipalidades e em pouco tempo tudo seria anarquia e desordem» (Archivo Municipal de Lisboa, sessão de 24/10/1881, p. 557). 


\section{A afirmação dos princípios da descentralização ao longo da década de $\mathbf{1 8 8 0}$}

A entrada em vigor da Lei de 2/5/1878 obrigou a articular a ação do pelouro da instrução com a da junta escolar, órgão consultivo de dimensão concelhia, a quem o legislador atribui amplas competências, muito particularmente a de graduar os candidatos ao magistério primário, bem como a de elaborar o plano geral provisório das escolas (Lei de 2/5/1878, artigos $30 .^{\circ}$ e $75 .^{\circ}$, respectivamente).

Leitura atenta merece, de resto, a intervenção da junta escolar do concelho de Lisboa. Para ela são nomeados, em outubro de 1881, Elias Garcia, João José de Sousa Teles e José Joaquim da Silva Amado, reitor do Liceu Nacional da capital. Não obstante a legitimidade da nomeação - os três vogais podiam ser escolhidos de entre os vereadores ou outros cidadãos (Regulamento de 28/7/1881, artigo 227. ${ }^{\circ}$ ) -, Teófilo Ferreira (1883) argumenta que só excecionalmente a junta escolar devia ser constituída por elementos estranhos à vereação. A razão que invoca é simples: evitar que a ação da junta escolar pudesse, em algum momento, colidir com os interesses da edilidade.

Não é difícil antecipar as orientações programáticas da junta escolar, se tivermos em conta que a presidência da mesma coube a Elias Garcia. A constatação mais imediata, assinalei-a já, é a de que as nomeações de professores para as escolas centrais ocorrem sem concurso documental, logo sem o parecer da junta. Uma infidelidade ao artigo $30 .^{\circ}$ da Lei de $2 / 5 / 1878$. Por outro lado, o encerramento das escolas paroquiais impugnava o artigo $73 .^{\circ}$ da citada lei, segundo o qual nenhum estabelecimento de ensino em exercício podia ser suprimido.

A questão, porém, que mais ocupa a junta escolar é seguramente a do plano geral provisório das escolas. A primeira versão do documento encontra-se pronta em outubro de 1881, manifestando desde logo a junta absoluta confiança nas virtudes da escola central (FERREIRA, 1883). O plano proposto espelha de facto essa crença, ao definir, nas suas linhas genéricas, uma rede de dezasseis escolas centrais para o conjunto dos três bairros administrativos da capital. E a este propósito não se pode deixar de sublinhar que a distribuição dos estabelecimentos de ensino teve em conta 
o número de habitantes de cada bairro. Outro critério foi o de assegurar igual oferta de escolas do sexo masculino e do sexo feminino.

Ora, esse mesmo plano contém já indicações acerca das escolas entretanto criadas pela Câmara (isto é, entre julho e outubro de 1881). Atente o leitor no próximo documento.

BAIRRO ORIENTAL

Três escolas centrais do sexo masculino.

Três escolas centrais do feminino.

Devendo entrar as actuais escolas da Câmara no plano, visto haver as escolas n.os 1 e 4 do sexo masculino e as n.os 5 e 7 do sexo feminino neste bairro, haverá somente a criar duas escolas, uma de cada sexo.

\section{BAIRRO CENTRAL}

Duas escolas do sexo masculino.

Duas escolas do sexo feminino.

Tendo a Câmara tomado posse da escola central que estava a cargo do Estado, estabelecida na rua de $\mathrm{S}$. José, haverá somente a criar uma escola do sexo masculino e duas do sexo feminino.

\section{BAIRRO OCIDENTAL}

Três escolas centrais do sexo masculino.

Três escolas centrais do sexo feminino.

Devendo entrar as actuais escolas da Câmara no plano, e por haver as escolas n.os 2 e 6 , haverá somente a criar uma escola do sexo masculino e três do sexo feminino.

FIGURA 1 - Documento I - Plano geral provisório das escolas (22/10/1881).

Fonte: FERREIRA, 1883.

No entanto, a junta logo alertava para o facto de o estabelecimento das escolas centrais exigir autorização do governo (Lei de 2/5/1878, artigo 
$\left.20 .^{\circ}\right)$. O circunstanciado e factual relato de Teófilo Ferreira, que continuarei a acompanhar, deixa perceber que a Câmara, por indicação de Elias Garcia ${ }^{9}$, solicitou efetivamente tal autorização. Não contou, todavia, que o governo devolvesse o assunto para ser novamente considerado pela edilidade. Julgo importante sublinhar o sentido histórico deste ato, uma vez que as escolas centrais do município de Lisboa nunca serão superiormente aprovadas. O que se impõe então dizer, sem detalhar a contenda que opôs as partes ao longo da década de 1880, é que o governo, preocupado em exercer um controlo político sobre a ação educativa do município, não apoiou o processo de renovação pedagógica em curso. Em rigor, tentou a todo o custo refreá-lo.

A partir de 1882, porém, com a chegada de Teófilo Ferreira à liderança do pelouro da instrução, a iniciativa reformadora da Câmara prossegue mais explícita nos seus objectivos e firmada numa série de medidas e de realizações.

Começo então por enfatizar um pressuposto da sua intervenção educativa: o de que uma experiência inovadora nas escolas municipais de Lisboa teria necessariamente de assentar num corpo docente qualificado. Em janeiro de 1883, 65\% dos professores do sexo masculino que leccionavam na capital possuíam o curso normal (SILVA, 2008); situação em grande parte resultante de um criterioso recrutamento de antigos alunos da Escola Normal, desde o final de 1881 (contornando, como se disse, a letra da Lei de 2/5/1878).

Consequentes foram, de facto, alguns projectos apadrinhados pelo município durante o mandato de Teófilo Ferreira (1882-1883). Entre eles, o da criação do Museu Pedagógico Municipal de Lisboa e da biblioteca anexa, encarados então como recurso determinante para o ensino intuitivo e para a própria renovação educacional. Deve, aliás, ser salientado o facto de as bibliotecas escolares, de igual modo consideradas bibliotecas municipais, isto é, abertas ao público, constituírem um importante eixo da política educativa do município no biénio de 1882-1883. De resto, uma das personalidades com relevante protagonismo nesse período é precisamente o bibliotecário-geral do município, Feio Terenas.

\footnotetext{
9 Elias Garcia mantém-se à frente do pelouro da instrução até ao final do ano de 1881 .
} 
Importa também dizer que é no mandato de Teófilo Ferreira, exatamente em abril de 1882, que se inaugura o jardim de infância Froëbel, situado no Passeio da Estrela. A ideia partira do próprio vereador da instrução, sensibilizado para esse tipo de instituições no Congresso Internacional de Pedagogia, realizado em Bruxelas no ano de 1880.

Não posso, ainda, deixar de referir o interesse de Teófilo Ferreira pelo ensino profissional. A primeira iniciativa nesse domínio apresentara-a na sessão da Câmara de 9/3/1882; tratava-se de um conjunto de propostas dizendo respeito à criação de aulas de desenho profissional, à abertura de cursos noturnos dessa disciplina, bem como à fundação de uma escola de aprendizes (FERREIRA, 1883). Uma iniciativa que, não obstante ter sido momentaneamente preterida, estará na origem da Escola Primária Superior Rodrigues Sampaio.

Finalmente, durante o biénio de 1882-1883 permanece firme a intenção de a Câmara expandir o número de escolas centrais (prescindindo sempre, como referi, da autorização do poder central). No entanto, sem o recenseamento das crianças em idade escolar não se podia definir com absoluta segurança o plano geral provisório das escolas, ao qual já me reportei. Quanto ao recenseamento - obrigatório nos termos da lei (Regulamento de 28/7/1881) -, é manifesta a dificuldade das juntas de paróquia cumprirem tal determinação ${ }^{10}$. Um assunto, aliás, de que se ocupará a junta escolar em 1884, presidida então pelo médico António Manuel da Cunha Belém.

É importante, por outro lado, situar as desconfianças da administração central relativamente às inovações pedagógicas do município de Lisboa. Há, obviamente, para além de razões de natureza política, motivos que se prendem com as verbas envolvidas. A este respeito, os próximos documentos falam certamente por si.

${ }^{10}$ Em dezembro de 1883 , no distrito de Lisboa, eram os seguintes os concelhos sem recenseamento escolar: Alenquer, Almada, Lisboa e Santiago do Cacém (AMORIM, 1884). 


\begin{tabular}{|l|r|r|r|r|}
\hline \multirow{2}{*}{ Distritos } & \multicolumn{2}{c|}{ Receita } & \multicolumn{2}{c|}{ Despesa } \\
\cline { 2 - 5 } & Orçada & Cobrada & Autorizada & \multicolumn{1}{c|}{ Paga } \\
\hline Aveiro & $25589 \$ 405$ & $21830 \$ 936$ & $24139 \$ 472$ & $22202 \$ 848$ \\
\hline Beja & $18187 \$ 193$ & $15937 \$ 687$ & $19040 \$ 243$ & $13744 \$ 915$ \\
\hline Braga & $18917 \$ 620$ & $12080 \$ 129$ & $21652 \$ 620$ & $17555 \$ 676$ \\
\hline Bragança & $27612 \$ 927$ & $21475 \$ 052$ & $28517 \$ 125$ & $21930 \$ 559$ \\
\hline Castelo Branco & $22869 \$ 499$ & $18155 \$ 011$ & $22941 \$ 914$ & $19432 \$ 447$ \\
\hline Coimbra & $29310 \$ 460$ & $25892 \$ 402$ & $29085 \$ 335$ & $25381 \$ 196$ \\
\hline Évora & $10911 \$ 005$ & $10066 \$ 793$ & $12338 \$ 100$ & $9118 \$ 827$ \\
\hline Faro & $17688 \$ 119$ & $12932 \$ 346$ & $17627 \$ 630$ & $10892 \$ 532$ \\
\hline Guarda & $32037 \$ 388$ & $26807 \$ 281$ & $39287 \$ 113$ & $30963 \$ 110$ \\
\hline Leiria & $16425 \$ 276$ & $15203 \$ 831$ & $18859 \$ 401$ & $14827 \$ 457$ \\
\hline Lisboa & $125121 \$ 839$ & $24373 \$ 957$ & $131126 \$ 374$ & $102412 \$ 370$ \\
\hline Portalegre & $17396 \$ 528$ & $16192 \$ 031$ & $13756 \$ 495$ & $11701 \$ 955$ \\
\hline Porto & $37155 \$ 263$ & $29433 \$ 560$ & $38042 \$ 526$ & $32759 \$ 783$ \\
\hline Santarém & $28654 \$ 338$ & $25908 \$ 434$ & $31097 \$ 638$ & $23890 \$ 793$ \\
\hline Viana do Castelo & $8218 \$ 200$ & $6932 \$ 282$ & $17942 \$ 200$ & $16336 \$ 571$ \\
\hline Vila Real & $17709 \$ 841$ & $10944 \$ 747$ & $32975 \$ 243$ & $28869 \$ 920$ \\
\hline Viseu & $57727 \$ 940$ & $46403 \$ 686$ & $56976 \$ 204$ & $45579 \$ 775$ \\
\hline \multicolumn{1}{|c|}{ Totais } & $511532 \$ 841$ & $340570 \$ 165$ & $555405 \$ 633$ & $447600 \$ 734$ \\
\cline { 2 - 5 }
\end{tabular}

FIGURA 2 - Documento II - Receitas votadas/despesas efectuadas pelas câmaras municipais com a instrução primária, por distrito (ano civil de 1882).

Fonte: AMORIM, 1884.

Nota: Valores em réis. O documento resume um mapa por concelhos. Se se disser que, no caso do município da capital, dos $90656 \$ 300$ réis de receita orçada e de despesa autorizada foram pagos $72968 \$ 495$ réis, percebemos as possibilidades da experiência descentralizadora no concelho de Lisboa relativamente aos demais.

E a verdade é que, no caso do município de Lisboa, as verbas afetas ao serviço de instrução não deixarão de aumentar ao longo da experiência descentralizadora. Para se ver, em 1886, ano em que a rede de escolas centrais estabiliza (num total de 22), se procede à sua reorganização e se amplia a estrutura do pelouro da instrução ${ }^{11}$, a verba orçada situar-se-á nos

${ }^{11}$ Devo dizer que, no seu mandato, Teófilo Ferreira não procede a alterações sensíveis na estrutura do pelouro da instrução. Relativamente ao seu antecessor (Elias Garcia, durante o 
$165400 \$ 000$ réis. Mas, para uma visão mais abrangente (mesmo para o período pós descentralização, na referência ao último ano do século XIX), atente o leitor no próximo documento.

\begin{tabular}{|c|c|c|c|}
\hline Julho de 1881 & 1886 & $1891-1892$ & 1900 \\
\hline $9568 \$ 955$ & $165400 \$ 000$ & $176123 \$ 080$ & $136123 \$ 000$ \\
\hline
\end{tabular}

FIGURA 3 - Documento III - Orçamentos de despesa com a instrução pública no município de Lisboa.

Fonte: Boletim do Serviço Geral de Instrucção Publica da Camara Municipal de Lisboa, n. 2, 1887; COELHO (1902); Decreto de 6/5/1892 (Diário do Governo, n. 103, de 9/5).

Nota: Valores em réis.

A melhor forma, porventura, de avaliar até onde foi a iniciativa do município de Lisboa durante o período de descentralização do ensino talvez seja através da análise do relatório que precede o Decreto de $6 / 5 / 1892$, pelo qual os serviços de instrução primária ficam sob a tutela do Estado. Ora, tal relatório baseava-se no trabalho de uma comissão nomeada em 10/10/1891, da qual fora presidente Bernardino Machado. Porém, a apreciação transcrita na folha oficial não coincide exactamente com as opiniões expressas pela citada comissão ${ }^{12}$.

E se é claro que as críticas apresentadas no citado relatório tem como móbil reduzir a despesa com a instrução primária, particularmente

segundo semestre de 1881, tinha procedido à criação dos lugares de encarregado do material das escolas e de adjunto à secretaria), há a assinalar a criação do lugar de visitador das escolas, para o qual foi nomeado, em 1883, Francisco Adolfo Coelho. O visitador, segundo o Regulamento Provisorio das Escolas Centraes (publicado pela Imprensa Nacional em 1883), era uma figura que, obrigatoriamente, teria de reunir com os regentes no final do ano letivo, propondo depois à Câmara «as modificações que a prática ou o progresso da pedagogia mostre ser conveniente introduzir nos programas e horários» (artigo 9. ${ }^{\circ}$ ). Mas tinha ainda por missão assistir às aulas dos professores, podendo, inclusive, interrogar os alunos para saber do seu aproveitamento (artigo 35. ${ }^{\circ}$ ). Acresce que presidia aos conselhos escolares por si convocados, tendo voto de qualidade (artigo 59..$^{\circ}$ ).

${ }^{12} \mathrm{O}$ trabalho elaborado pela comissão foi parcialmente publicado em Machado (1896); na obra em questão não se reproduz o corpo de anexos (mapas vários relativos à estatística escolar, às condições higiénicas dos edifícios...). Todavia, esses elementos informativos podem ser consultados no Museu Bernardino Machado (MBM), em Vila Nova de Famalicão (MBM, Escolas Municipais de Lisboa. Condições gerais - pedagógicas e higiénicas, cota 271 B). 
no concelho de Lisboa (defende-se, a dado passo, que durante a década de descentralização o número de alunos não chegara a triplicar mas a despesa, essa, aumentara mais de $2000 \%$ ), não menos patente é, por vezes, sob esse mesmo pressuposto, verberarem-se iniciativas de indiscutível mérito. Um exemplo elucidativo:

A escola «Maria Pia», igualmente considerada pela câmara como de ensino primário superior, é antes um instituto de instrução secundária para o sexo feminino, porque compreende quase todas as disciplinas que constituem o curso dos liceus (Decreto de 6/5/1892).

É, de facto, em nome de pressupostos económicos que o governo não apadrinha os processos de modernização pedagógica em curso nas escolas municipais de Lisboa. Mas, em certa medida, a crítica passa também pela ideia de que o município excedera as suas competências, chegando, por exemplo, a criar um serviço de inspecção escolar e, mesmo, uma escola de habilitação para o magistério primário.

No entanto, um ator como Bernardino Machado não deixará de condenar a posição do governo. Muito a propósito encerro com uma missiva que o eminente professor de Coimbra dirigiu a Francisco Giner de los Ríos, poucos dias após a publicação do citado Decreto de 6 de maio de 1892.

FIGURA 4 - Documento IV - Carta de Bernardino Machado a Francisco Giner de los Ríos, catedrático da Universidade de Madrid (13/5/1892).

Fonte: Academia Real de História (Madrid), Fundo Giner de los Ríos, Cx. 7-135.

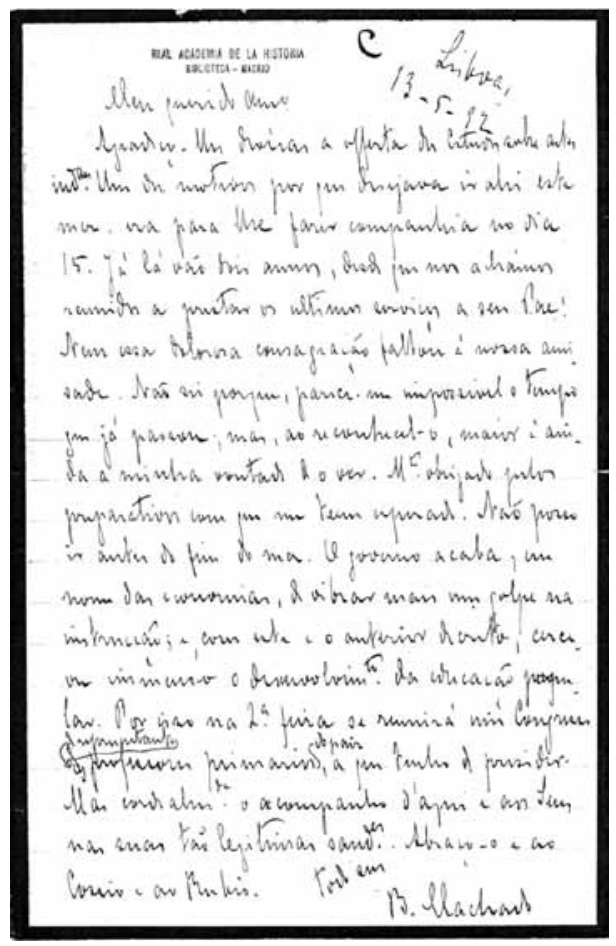




\section{Concluindo...}

Ao longo da primeira grande experiência descentralizadora do ensino em Portugal, o município de Lisboa, sob a égide de maçons republicanos, põe em prática um projeto de educação e de promoção cultural digno da maior nota. As dinâmicas então criadas, convém sublinhá-lo, ilustram bem a importância de existir um compromisso profundo entre a escola e a comunidade educativa. Mais, grande parte das iniciativas que foram sendo relatadas - pensemos, por exemplo, na aposta no modelo de escola graduada, na criação de bibliotecas escolares e municipais, na fundação do Museu Pedagógico Municipal, na promoção da educação infantil pelo método fröoebeliano, entre outras -, são fortemente alicerçadas em decisões tomadas no plano local, o mesmo é dizer, adaptadas ao terreno pedagógico (refreadas, porém, pelo poder central). Mas, obviamente, a ideia que fica expressa é a do potencial da gestão local da educação para a inovação.

Num país marcado pelo atraso educacional, impõe-se enfatizar o esforço das elites republicanas no sentido de criar um sistema escolar comparável ao dos outros países da Europa; sublinha-se, assim, a importância de pensar com ousadia a ação pedagógica.

\section{Referências}

AMORIM, António Maria. Dados para o Relatório sobre Instrução Primária que o governo tem de bienalmente apresentar, Ano lectivo de 1882-1883, 1884 (documento em depósito no Museu Bernardino Machado).

Código Administrativo aprovado por carta de lei de 6 de maio de 1878 . Lisboa: Imprensa Nacional, 1890.

COELHO, Francisco Adolfo. As despesas do ensino em Portugal no fim do século XIX, O Instituto, Coimbra, v.8, n. 49, p. 449-463. 1902.

FERNANDES, Rogério. Bernardino Machado e os Problemas da Instrução Pública. Lisboa: Livros Horizonte, 1985.

FERREIRA, Teófilo. Relatorio do pelouro da instrucção da Câmara Municipal de Lisboa relativo ao anno civil de 1882. Lisboa: Typographia Nova Minerva, 1883. 
. O Ministerio da Instrucção Publica e a centralisação do ensino primario official. Lisboa: Imprensa Nacional, 1890.

GHIRA, Mariano. Actas das Sessões das Conferencias Pedagogicas feitas no Lyceu Nacional de Lisboa no Anno Lectivo de 1867 a 1868 sob a Presidencia de Mariano Ghira, Comissario dos Estudos do Districto e Reitor do Mencionado Lyceu. Lisboa: Imprensa de Júlio C. Pereira Coutinho, 1868.

MACHADO, Bernardino. A organisação do Ministerio d'Instrucção Publica e a centralisação do ensino official especialmente do ensino primário. Lisboa: Imprensa Nacional, 1890.

- Affirmações Publicas (1888-1893). Coimbra: Imprensa da Universidade, 1896.

Regulamento Provisorio das Escolas Centraes do Municipio de Lisboa. Lisboa: Imprensa Nacional, 1883.

SILVA, Carlos Manique da. Do modo de aprender e de ensinar. Renovação pedagógica e cenários de experimentação da escola graduada (18341892). 2008. 381f. Tese (Doutorado em Educação) - Faculdade de Psicologia e de Ciências da Educação da Universidade de Lisboa, 2008.

Data de registro: $13 / 01 / 2012$

Data de aceite: 21/03/2012 